\title{
The effects of sling exercise program on balance and body activities in children with spastic cerebral palsy
}

\author{
Eun-Ju Song' ${ }^{1}$ Eun-Jung Lee ${ }^{2}$, Hae-Yeon Kwon ${ }^{3, *}$ \\ 'Busan Brain Lesion Welfare Center, Busan, Korea \\ ¿Ulsan Community Rehabilitation Center, Ulsan, Korea \\ ${ }^{3}$ Department of Physical Therapy, College of Nursing and Healthcare Science, Dong-Eui University, Busan, Korea
}

The purpose of this study was to investigate the static and dynamic balance and body activities after administering a trunk stability exercise program using a sling for children with spastic cerebral palsy of Gross Motor Function Classification System (GMFCS) levels III-IV. This study was conducted based on a quasi-experimental study design. Six of the study participants were assigned to the control group and six were assigned to the experimental group using simple random sampling. Both groups underwent a double-blind clinical trial study in which exercise therapy was performed for 40 min twice a week for 8 weeks. The experimental group underwent the sling exercise program and the control group underwent neuro-developmental treatment. The results showed that static and dynamic balance were significantly different before and after intervention in both the experimental and control groups $(P<0.05)$, and there was also a statistically significant difference between the two groups $(P<0.05)$. Gross motor function and activities of daily life showed significant improvement before and after intervention in the experimental group $(P<0.05)$, but there was no statistically significant difference in the control group $(P<0.05)$. There was a statistically significant difference between the two groups $(P<0.05)$. Therefore, the sling exercise program can be used as an effective treatment for improving balance and physical activity in children with cerebral palsy of GMFCS levels III-IV who have difficulty walking. In addition, such exercise will have a positive impact on the independence of such children and help them to participate in social activities.

Keywords: Cerebral palsy, Sling exercise training, Trunk stability, Balance, Motor function

\section{INTRODUCTION}

Cerebral palsy is a nonprogressive central nervous system lesion that occurs in the developing brain before, during, or after birth that can change in course but causes permanent neurodevelopmental disorders (Brunner and Cuestas, 2019). Children with cerebral palsy are accompanied by musculoskeletal problems along with complex disorders such as cognitive, communication, sensory, perceptual, behavioral disorders, and epilepsy (Rosenbaum et al., 2007). Among the various problems, the defect in the trunk stabilization directly affects the balancing ability and functional movement (Lee et al., 2020). Primarily, weakness of the abdominal and trunk muscles, a musculoskeletal problem, causes trouble in postural stability and balance, and as a result when performing gross motor functions such as sitting, standing, and walking, the ability to control posture decreases and limits in activities of daily living appear (Krigger, 2006).

The ability to balance is an essential element of gross motor function and activities of daily living (Yavuzer et al., 2006). Balancing can be divided into static balance and dynamic balance, where static balance refers to the ability to maintain balance on a fixed support surface without shaking, while dynamic balance refers to the ability to maintain posture alignment when carrying out movements (Haliloglu et al., 2019). Insufficient balancing ability causes compensatory movements of the head or upper arm to maintain posture, and abnormal aspects in postural response, balance response, and functional movement occur, resulting in secondary dysfunction (Araújo et al., 2020). Among the balancing
${ }^{*}$ Corresponding author: Hae-Yeon Kwon (iD https://orcid.org/0000-0002-8345-6315 Department of Physical Therapy, College of Nursing and Healthcare Science, Dong-Eui University, 176 Eomgwangno, Busanjin-gu, Busan 47340, Korea Email: sunlotus75@deu.ac.kr

Received: October 21, 2021 / Accepted: November 19, 2021
This is an Open Access article distributed under the terms of the Creative Commons Attribution Non-Commercial License (https://creativecommons.org/licenses/by-nc/4.0/) which permits unrestricted non-commercial use, distribution, and reproduction in any medium, provided the original work is properly cited. 
abilities in various postures, the ability to balance sitting posture affects the children's learning and task performance, and thus is deemed to be a basis of daily life and social activities (Santamaria et al., 2020) Particularly, for children who have difficulty in standing and are incapable of walking, the ability to balance sitting posture has a greater influence on the daily life (Inamdar et al., 2021). In conclusion, insufficient trunk stabilization causes a limitation on the balancing ability, which not only affects the functional movement but also reduces the sensorimotor adaptation ability depending on various environmental changes and tasks, resulting in restrictions on the daily life and participation of the social activity (Himmelmann and Uvebrant, 2018).

The methods for stabilizing the trunk being applied in the clinical trials include various intervention methods, such as therapy training using horseback riding equipment, therapy using virtual reality, neurodevelopmental treatment, etc. (Dewar et al., 2015). One of the treatment methods to provide an unstable support surface, the sling exercise utilizes various axis changes through the hanging string (Kim et al., 2018b). This is an effective treatment method for muscle strengthening exercise because the effects of joint mobility and elongation, increase and relaxation of muscular endurance, and stabilization of the trunk can be obtained through this treatment (Chen et al., 2016). In addition, slings can be used as a means of assistance during exercise to reduce passive factors and enable active treatment participation of the subject (Vikne et al., 2007). When the activation of specific muscles is promoted using a sling can provide greater activation to the subject and a higher degree of freedom to the therapist (Maeo et al., 2014).

Although there are previous studies that trunk stabilization exercise using a sling is effective in stabilizing the trunk, most of the studies that applied sling exercise therapy in the clinical setting were for musculoskeletal patients. In addition, studies on central nervous system patients are often applied to adults or children with cerebral palsy of Gross Motor Function Classification System (GMFCS) levels I-II, so objective data are insufficient for children with cerebral palsy in levels III-IV, who have difficulty walking. Therefore, the purpose of this study is to investigate the effects of a trunk stabilization exercise program using a sling on static and dynamic balance and body activities of daily living in children with spastic cerebral palsy who have difficulty walking.

\section{MATERIALS AND METHODS}

\section{Participants}

This study has a quasi-experimental design for children diag- nosed with cerebral palsy and receiving physical therapy at medical and health institutions in Busan and Ulsan. These are all children under the age of 11 with spastic cerebral palsy, which fall into GMFCS levels III-IV, and are children with a cognitive level that can understand the therapist's instructions. However, children who were taking drugs related to spasms and seizures or who had undergone surgery or chemical procedures to reduce spasticity were excluded. All participants and their guardians participated in this study voluntarily after being explained the research purpose and method in detail, and the study was approved by the Bioethics Committee of Dong-Eui University to comply with the Bioethics and Safety Act (IRB No. DIRB-201909-HR-R-20).

\section{Sling exercise program}

In this study, 12 participants were randomly divided into an experimental group and a control group with 6 participants in each group, and the experiment was conducted for 8 weeks. For measurement, a physical therapist with more than 5 years of experience, not a researcher, performed an evaluation related to balance and gross motor function before and after the intervention. For the intervention, the experimental group applied the sling exercise program, and the control group applied neurodevelopmental therapy twice a week for $40 \mathrm{~min}$. The sling exercise program was conducted using a sling exercise tool (Redcord, Oslo, Norway) by a physical therapist with more than 5 years of experience that completed professional training in the central nervous system. Table 1 details the modified method for this participant's characteristics, with reference to Park and Hwangbo (2014).

\section{Outcome measurements}

This study was a randomized, double-blind, placebo comparison that provided the participants and the measurer, excluding the researchers, minimal information about the participants participating in the experiment, so the study proceeded with a physical therapist with more than 5 years of experience that is not a researcher as the measurer in an intensive care unit where the child's performance is not disturbed. Before the study, the measurer showed and explained a demonstration so that the children could understand the correct movement, and then all children were subjected to the same conditions.

\section{Static/dynamic balance}

For the evaluation of balancing ability, BioRescue balance analysis system (RM Ingenierie, Rodez, France) was used. This measuring tool can check the participant's balancing ability and weight 
Table 1. Sling exercise program

\begin{tabular}{|c|c|c|}
\hline Exercise & Position & Exercise program \\
\hline Warm-up exercise (5 min) & Hook-lying & Pelvic posterior tilt exercise in the hook-lying position for activate the abdominal and trunk muscles. \\
\hline \multirow[t]{4}{*}{ Main exercise (30 min) } & Prone on elbow & $\begin{array}{l}\text { The knee is supported by a sling, and a foam roller is positioned at the abdomen to induce stability of the shoulder joint } \\
\text { and stabilization of the trunk. }\end{array}$ \\
\hline & Quadruped & $\begin{array}{l}\text { To reduce weight load a sling is applied to the trunk, quadruped position is maintained with quadruped motions are } \\
\text { performed repeatedly. }\end{array}$ \\
\hline & Kneel stand & $\begin{array}{l}\text { Support forearm on the platform connected to the sling, and tilt body forward, hold the position for } 3-5 \text { sec to contract the } \\
\text { stabilizing muscles, and then returns to the starting position. }\end{array}$ \\
\hline & Sitting & $\begin{array}{l}\text { Hold the handle with both hands on the platform and the therapist pushes the platform forward, inducing pelvic anterior } \\
\text { and posterior tilt as well as head and trunk equilibrium reactions. }\end{array}$ \\
\hline Cool-down exercise (5 min) & Supine & $\begin{array}{l}\text { In the supine position, flex the hips and knees and hold the knees with two hands. Then take deep breaths while relaxing } \\
\text { the shoulders, abdomen, and lower back. }\end{array}$ \\
\hline
\end{tabular}

bearing in various postures, and it is easy to check the data because the measurement results are displayed on the computer screen as numerical values and graphs. In addition, it is known that it is possible to measure and train a variety of participants, including children with cerebral palsy, in symmetry in weight bearing and balancing ability (Han et al., 2019).

In this study, to exclude changes due to leg tension, ankle foot orthosis was worn if necessary, and the static and dynamic stability was measured by measuring the total surface area and length of the center of gravity of the body in a sitting position. For the starting posture for measurement, the hip joint and knee joint of the participant were mad at $90^{\circ}$ each, and the participant was asked to sit in an upright posture and to stare at the front. The sole of the foot was to touch the ground at this time, and a footrest was provided to ensure safety when the sole of the foot did not touch the ground. When measuring static balance, as the measurer signaled 'start' the participants bent both shoulder joints to $90^{\circ}$ and fully extended the elbow joint, raising the arm and holding it for $12 \mathrm{sec}$. When measuring dynamic balance, as the measurer signaled 'start' the participants bent both shoulder joints and elbow joints at $90^{\circ}$ and performed eight hand claps (Lee et al., 2021). Both measurements were repeated 3 times per participant, and the average value was calculated. Furthermore, the effect on muscle fatigue was minimized by taking a 5 -min break between each measurement. The measurement was carried out in a quiet room considering that children with cerebral palsy are easily distracted and not able to concentrate for a long time.

\section{Gross motor function}

To evaluate the change in gross motor function, the Gross Motor Function Measure-88 (GMFM-88) was used, which can be applied to children with cerebral palsy and Down syndrome that are
5 months to 16 years of age. There are five measurement areas of this evaluation tool, and the scores and total points for each area are converted into raw scores and percentages and recorded. The score was graded on a 4-point ordinal scale from 0-3 points, and there are definitions for partial and complete performances of each item in the evaluation execution and scoring guide, and the evaluator was fully aware of this. GMFM-88 had an intrainspector reliability of 0.91 , a test-retest reliability of 0.998 , and an inter-inspector reliability of 0.997 , which proved to be a discriminatory and sensitive tool (Rosenbaum et al., 2002).

\section{Activities of daily living}

The activities of daily living were measured using the Functional Independence Measure for children (Wee-FIM), a tool made by modifying and supplementing the Functional Independence Measure (FIM). Wee-FIM is applicable to general children aged 6 months to 7 years, children with developmental disabilities aged 6 months to 12 years, children with a living mental age of 7 years or younger, to evaluate their functional independence (Park et al., 2013). This tool includes six evaluation items and 18 subordinate items for each item. Each item is on a 7-point scale, and the total score may be calculated within a range of at least 18 up to 126 points (Msall et al., 1994). This is a measuring tool with a verified and standardized reliability, which has a test-retest reliability of 0.83 to 0.99 and an inter-inspector reliability of 0.74 to 0.96 (Ottenbacher et al., 2000).

\section{Data analysis}

The data measured in this study were analyzed using the IBM SPSS Statistics ver. 25.0 (IBM Co., Armonk, NY, USA), and the statistical significance level $(\alpha)$ was set to 0.05 . After confirming the assumption of normality of the measured variables through 
Table 2. General characteristics of each group

\begin{tabular}{lcccc}
\hline Characteristic & Experimental $(\mathrm{n}=6)$ & Control $(\mathrm{n}=6)$ & $Z$ & $P$-value \\
\hline Gender & & & 0.00 & 1.00 \\
Male & $2(33)$ & $2(33)$ & & \\
Female & $4(67)$ & $4(67)$ & & \\
Age & $6.66 \pm 2.73$ & $6.50 \pm 2.88$ & -0.08 & 0.93 \\
Height $(\mathrm{cm})$ & $113.00 \pm 14.96$ & $111.83 \pm 16.36$ & -0.16 & 0.87 \\
Weight $(\mathrm{kg})$ & $23.50 \pm 7.42$ & $20.50 \pm 6.28$ & -0.56 & 0.57 \\
Gestational age $(\mathrm{wk})$ & $29.16 \pm 2.22$ & $31.33 \pm 4.63$ & -1.04 & 0.29 \\
Birth weight $(\mathrm{g})$ & $1,550.00 \pm 266.45$ & $1,850.00 \pm 327.10$ & -1.54 & 0.12
\end{tabular}

Values are presented as number (\%) or mean \pm standard deviation.

Table 3. Comparison of balance between before and after treatment

\begin{tabular}{|c|c|c|c|c|c|}
\hline Variable & Group & Pre & Post & $Z$ & $P$-value \\
\hline \multicolumn{6}{|l|}{ Static balance } \\
\hline \multirow{2}{*}{$\begin{array}{l}\text { Surface area } \\
\text { ellipse }\left(\mathrm{mm}^{2}\right)\end{array}$} & Experimental & $242.16 \pm 104.57$ & $42.50 \pm 45.43$ & -2.20 & $0.02^{*}$ \\
\hline & Control & $126.33 \pm 66.41$ & $101.33 \pm 53.57$ & -2.20 & $0.02^{*}$ \\
\hline \multirow[t]{2}{*}{ Length (cm) } & Experimental & $11.20 \pm 8.85$ & $4.95 \pm 4.43$ & -2.20 & $0.02^{*}$ \\
\hline & Control & $10.98 \pm 7.82$ & $9.13 \pm 6.13$ & -2.20 & $0.02^{*}$ \\
\hline \multicolumn{6}{|l|}{ Dynamic balance } \\
\hline \multirow{2}{*}{$\begin{array}{l}\text { Surface area } \\
\quad \text { ellipse }\left(\mathrm{mm}^{2}\right)\end{array}$} & Experimental & $334.50 \pm 167.47$ & $59.00 \pm 40.39$ & -2.20 & $0.02^{*}$ \\
\hline & Control & $188.00 \pm 94.25$ & $162.33 \pm 85.24$ & -2.20 & $0.02^{*}$ \\
\hline \multirow[t]{2}{*}{ Length (cm) } & Experimental & $16.30 \pm 10.56$ & $6.68 \pm 4.77$ & -2.20 & $0.02^{*}$ \\
\hline & Control & $13.23 \pm 10.60$ & $11.95 \pm 10.61$ & -2.20 & $0.02^{*}$ \\
\hline
\end{tabular}

Values are presented mean \pm standard deviation.

${ }^{*} P<0.05$.

the Shapiro-Wilk test, a nonparametric method was implemented. Changes in balance and gross motor function before and after treatment in the experimental group and the control group that were subjected to the sling exercise program were analyzed by the Wilcoxon Signed-Rank test, and the difference in measurement results between the experimental group and the control group was analyzed by the Mann-Whitney test.

\section{RESULTS}

The participants of the study were four males and eight females out of a total of 12 , average age was $6.58 \pm 2.68$ years old, the average height was $112.42 \pm 14.96 \mathrm{~cm}$, and the average weight was $22.00 \pm 6.74 \mathrm{~kg}$. The general characteristic of the experimental group and the control group were tested for homogeneity before intervention, and as a result, there was no significant difference between the two groups. Details are shown in Table 2 .
Table 4. Difference between the two groups in changes of balance

\begin{tabular}{lcccc}
\hline Variable & Experimental & Control & $Z$ & $P$-value \\
\hline Static Balance & & & & \\
$\quad$ Surface area ellipse $\left(\mathrm{mm}^{2}\right)$ & $-199.66 \pm 68.37$ & $-25.00 \pm 17.20$ & -2.88 & $0.00^{*}$ \\
Length $(\mathrm{cm})$ & $-6.25 \pm 4.62$ & $-1.85 \pm 1.87$ & -2.00 & $0.04^{*}$ \\
Dynamic Balance & & & & \\
$\quad$ Surface area ellipse $\left(\mathrm{mm}^{2}\right)$ & $-275.50 \pm 127.33$ & $-25.66 \pm 15.26$ & -2.88 & $0.00^{*}$ \\
Length $(\mathrm{cm})$ & $-9.61 \pm 6.20$ & $-1.28 \pm 0.67$ & -2.88 & $0.00^{*}$ \\
\hline
\end{tabular}

Values are presented mean \pm standard deviation.

${ }^{*} P<0.05$.

Table 5. Comparison of GMFM score between before and after treatment

\begin{tabular}{llcccc}
\hline Variable & \multicolumn{1}{c}{ Group } & \multicolumn{1}{c}{ Pre } & Post & $Z$ & $P$-value \\
\hline GMFM D & Experimental & $69.23 \pm 16.45$ & $78.20 \pm 16.19$ & -2.02 & $0.04^{*}$ \\
$\begin{array}{l}\text { (standing) } \\
\text { GMFM E (walking, }\end{array}$ & Control & $51.71 \pm 20.27$ & $52.99 \pm 21.97$ & -1.34 & 0.18 \\
$\begin{array}{l}\text { running, } \\
\text { jumping) }\end{array}$ & Control & $28.70 \pm 25.18$ & $29.40 \pm 26.32$ & -1.34 & 0.18 \\
GMFM total & Experimental & $82.03 \pm 9.15$ & $85.54 \pm 8.58$ & -2.20 & $0.02^{*}$ \\
& Control & $72.25 \pm 9.91$ & $73.11 \pm 10.98$ & -1.60 & 0.10 \\
\hline
\end{tabular}

Values are presented mean \pm standard deviation.

GMFM, Gross Motor Function Measure.

${ }^{*} P<0.05$.

\section{Static/dynamic balance}

The within-group effect can be confirmed in Table 3. In the within-group effect test, there was a statistically significant difference between the static and dynamic balance mean values of the experimental group and the control group before and after the intervention. There was also a significant difference in the value of the difference in the sway area and length of the static and dynamic balance between the groups, which can be confirmed in Table 4 .

\section{Gross motor function}

There was a statistically significant difference in the scores and total scores of the D (standing), E (walking, running, jumping) areas before and after the intervention in the experimental group. The control group did not show a significant difference, which can be seen in Table 5 . There was a statistically significant difference between the experimental group and the control group before and after the intervention for the score of each area and the total score (Table 6).

\section{Activities of daily living}

The total score of the daily living activities shows a significant difference in the experimental group before and after the intervention in the within-group effect test, but not in the control group, 
Table 6. Difference between the two groups in change of GMFM score

\begin{tabular}{lcccc}
\hline Variable & Experimental & Control & $Z$ & $P$-value \\
\hline GMFM D (standing) & $8.97 \pm 6.83$ & $1.28 \pm 2.14$ & -2.24 & $0.02^{*}$ \\
GMFM E (walking, running, jumping) & $4.85 \pm 4.00$ & $0.69 \pm 1.16$ & -2.37 & $0.01^{*}$ \\
GMFM total & $3.50 \pm 0.91$ & $0.86 \pm 1.44$ & -2.41 & $0.01^{*}$ \\
\hline
\end{tabular}

Values are presented mean \pm standard deviation.

GMFM, Gross Motor Function Measure.

${ }^{*} P<0.05$.

Table 7. Comparison of Wee-FIM score between before and after treatment

\begin{tabular}{lcccc}
\hline Group & Pre-treat & Post-treat & $Z$ & $P$-value \\
\hline Self-care & & & & \\
Experimental & $32.50 \pm 6.31$ & $34.00 \pm 5.58$ & -2.04 & $0.04^{*}$ \\
Control & $30.66 \pm 6.21$ & $31.00 \pm 5.93$ & -1.41 & 0.15 \\
Sphincter control & & & & \\
Experimental & $13.66 \pm 0.51$ & $13.66 \pm 0.51$ & 0.00 & 1.00 \\
Control & $13.83 \pm 0.40$ & $13.83 \pm 0.40$ & 0.00 & 1.00 \\
Mobility: transfer & & & & \\
Experimental & $16.66 \pm 3.55$ & $17.33 \pm 3.77$ & -2.00 & $0.04^{*}$ \\
Control & $14.50 \pm 4.76$ & $14.83 \pm 4.99$ & -1.41 & 0.15 \\
Locomotion & & & & \\
Experimental & $11.50 \pm 1.51$ & $11.83 \pm 1.72$ & -1.41 & 0.15 \\
Control & $9.66 \pm 1.03$ & $9.66 \pm 1.03$ & 0.00 & 1.00 \\
Communication & & & & \\
Experimental & $12.66 \pm 1.03$ & $12.66 \pm 1.03$ & 0.00 & 1.00 \\
Control & $13.16 \pm 1.32$ & $13.16 \pm 1.32$ & 0.00 & 1.00 \\
Social cognition & & & & \\
Experimental & $17.33 \pm 3.82$ & $17.50 \pm 3.72$ & -1.00 & 0.31 \\
Control & $18.83 \pm 1.60$ & $18.83 \pm 1.60$ & 0.00 & 1.00 \\
Total Wee-FIM & & & & \\
Experimental & $104.33 \pm 11.09$ & $107.00 \pm 10.01$ & -2.22 & $0.02^{*}$ \\
Control & $100.66 \pm 10.51$ & $101.33 \pm 10.80$ & -1.63 & 0.10 \\
\hline
\end{tabular}

Values are presented mean \pm standard deviation.

Wee-FIM, Functional Independence Measure for children.

${ }^{*} P<0.05$.

which can be confirmed in Table 7 . There was a statistically significant difference between the total score values of the experimental group and the control group before and after the intervention, and the specific differences in each area and in the total score can be confirmed in Table 8 .

\section{DISCUSSION}

This study was conducted to investigate the effects of a sling exercise program for trunk stability on static and dynamic balance and body activities in a sitting posture for children with spastic cerebral palsy.
Table 8. Difference between the two groups in change of Wee-FIM score

\begin{tabular}{lcccc}
\hline Dimension & Experimental & Control & $Z$ & $P$-value \\
\hline Self-care & $1.50 \pm 1.04$ & $0.33 \pm 0.51$ & -2.03 & $0.04^{*}$ \\
Sphincter control & $0.00 \pm 0.00$ & $0.00 \pm 0.00$ & 0.00 & 1.00 \\
Mobility: transfer & $0.66 \pm 0.51$ & $0.33 \pm 0.51$ & -1.10 & 0.26 \\
Locomotion & $0.33 \pm 0.51$ & $0.00 \pm 0.00$ & -1.48 & 0.13 \\
Communication & $0.00 \pm 0.00$ & $0.00 \pm 0.00$ & 0.00 & 1.00 \\
Social cognition & $0.16 \pm 0.40$ & $0.00 \pm 0.00$ & -1.00 & 0.31 \\
Total Wee-FIM & $2.66 \pm 1.50$ & $0.66 \pm 0.81$ & -2.39 & $0.01^{*}$
\end{tabular}

Values are presented mean \pm standard deviation.

Wee-FIM, Functional Independence Measure for children.

${ }^{*} P<0.05$.

For children with cerebral palsy, trunk stability and the ability to balance sitting posture are essential for performing hand movements such as playing and eating, and for children who have difficulty standing or walking, it is even more important for a smooth wheelchair life (Kim et al., 2018a). In a meta-analysis that summarized nine studies targeting stroke patients with limited balance ability, sling exercise training treatment combined with existing rehabilitation treatment could improve balance function after stroke (Chen et al., 2016), and research by Park and Hwangbo (2014) also claimed that sling exercise therapy is effective in trunk stability and balance. In a study by Moraes et al. (2016), trunk muscle strength reinforcement using horseback riding therapy was performed twice a week for 30 min for 12 weeks in children with cerebral palsy, and it was found that the sway distance and sway speed were significantly reduced in the sitting position. This is consistent with the study result that both static/dynamic balance of the experimental group to which the sling exercise program was applied was significantly improved. The sling exercise therapy is a dynamic state exercise conducted on an unstable support surface (Park et al., 2015). In a treatment applied in clinical practice, exercise in static and dynamic state is applied to improve balancing ability, and among them, exercise in a dynamic state induces more muscle activity and increases the sense of balance and posture maintaining ability (Lehman et al., 2005; Schubert et al., 2008). Movement in an anxious environment promotes dynamic balance and postural control over movement in a stable environment because it can potentially alter the order of neuromuscular recruitment patterns (Nepocatych et al., 2018). In other words, performing exercise using a therapeutic ball or sling rather than in an environment such as a fixed ground stimulates the motor organs of the cerebrum and stimulates proprioceptors to maximize the sense of balance and ability to maintain balance (O'Sullivan et al., 1997). Moreover, it is believed that the inclusion of a 
closed-kinetic chain motion that enhances joint stability and support of limbs and promotes simultaneous contraction of agonist and antagonist muscles in the program composition promoted trunk stabilization of the participant and improved balance (Dannelly et al., 2011).

Casady and Nichols-Larsen (2004) reported a significant increase in gross motor function when horseback riding treatment was applied for 10 weeks for $45 \mathrm{~min}$ for trunk stabilization to children with cerebral palsy, and in a study by Ko et al. (2016), which applied a sling exercise therapy for 40 min twice a week for 6 weeks to infants and toddlers with developmental disabilities, significant improvement in gross motor function was also observed. All previous studies conducted programs for trunk stabilization and led improvements in children's gross motor functions, and even in this study a significant improvement in gross motor function was confirmed after 8 weeks of trunk stabilization sling exercise program, which matches with results from previous studies. The sling exercise program used for trunk stabilization in this study is a sensory-motor control training, and the training proceeds by repeating the same motion in a moving string. This is to recreate the engram for the movement in the center, and it not only improves the stability of the trunk, but also improves the ability to control the trunk and align posture, and promotes movement (Lee and Lee, 2014). This improvement of trunk control and posture alignment ability induces the promotion of movement such as functional movement, so it is considered that there was a significant improvement in the gross motor function.

The meta-analysis by Chen et al. (2016) claimed, based on nine studies, that sling exercise training treatment has a superior effect of improving the functional independence than the existing rehabilitation treatments. The functional independence of the participant was measured using Barthel index score, which can be used as the same measure as FIM (Prodinger et al., 2017). The Wee-FIM used in this study is a tool which was modified from FIM to be used for children, so it has the same evaluation items, differing only in target age. Thus, the before-and-after significant difference of the experimental group in the score of the daily living activities shown in the result of this study can be interpreted as the result that is consistent with that of the precedent study. The sling reduces the weight bearing of parts of the body so that even those who lack motor ability can actively participate in the exercise and control their own movements while having the opportunity to train for proprioception and neuromuscular control (Choi and Kang, 2013). Thus, it can be said that more efficient and functional active exercise is possible (Jung and Choi, 2019). Since the sling ex- ercise is conducted based on positive participation, it can be helpful to improve the function and the quality of life as well as the static posture alignment (Mau-Moeller et al., 2014).

As such, the results of this study suggest that the sling exercise program for trunk stabilization is effective in improving children's balance and body activities, and the results may emphasize the importance of active treatment participation and trunk control in the treatment of children with spastic cerebral palsy and recommend the application of sling exercise program for children who lack trunk stability. Also, according to the result of this study, the active treatment approach has a higher connection to the functional areas of the physical activity than the passive one. This can be deemed to be meaningfully applicable to children with disabilities who have limitations on the social engagement because of taking more time to do self-management in daily life.

However, the participant is a child with spastic cerebral palsy, so it is difficult to apply this to all types of cerebral palsy, and among the children with spastic cerebral palsy accounting for $60 \%$ to $70 \%$ of the entire children with cerebral palsy, only the children who fall into GMFCS level III to IV were selected as the participant, and thus it is difficult to make a generalization and interpretation because of the small number of participants. In addition, due to environmental and ethical issues, it was difficult to completely control the participant's treatment at other institutions because the experiment was designed as a quasi-experimental design. In the future, it is expected that observation over time or studies targeting children with more various types of cerebral palsy will continue to provide evidence for the development of a more systematic sling exercise program and an active treatment approach.

\section{CONFLICT OF INTEREST}

No potential conflict of interest relevant to this article was reported.

\section{ACKNOWLEDGMENTS}

The authors received no financial support for this article.

\section{REFERENCES}

Araújo PA, Starling JMP, Oliveira VC, Gontijo APB, Mancini MC. Combining balance-training interventions with other active interventions may enhance effects on postural control in children and adolescents with cerebral palsy: a systematic review and meta-analysis. Braz J 
Phys Ther 2020;24:295-305.

Brunner MMR, Cuestas E. The construction of cerebral palsy definition: a historical journey to the present. Rev Fac Cien Med Univ Nac Cordoba 2019;76:113-117.

Casady RL, Nichols-Larsen DS. The effect of hippotherapy on ten children with cerebral palsy. Pediatr Phys Ther 2004;16:165-172.

Chen L, Chen J, Peng Q, Chen J, Zou Y, Liu G. Effect of sling exercise training on balance in patients with stroke: a meta-analysis. PLoS One 2016;11:e0163351.

Choi YG, Kang HK. The effects of sling exercise using vibration on trunk muscle activities of healthy adults. J Phys Ther Sci 2013;25:1291-1294.

Dannelly BD, Otey SC, Croy T, Harrison B, Rynders CA, Hertel JN, Weltmen $A$. The effectiveness of traditional and sling exercise strength training in women. J Strength Cond Res 2011;25:464-471.

Dewar R, Love S, Johnston LM. Exercise interventions improve postural control in children with cerebral palsy: a systematic review. Dev Med Child Neurol 2015;57:504-520.

Haliloglu O, Topsakal N, Camliguney F, Korkmaz OP, Sahin S, Cotuk B, Kadioglu P, Erkut O. Static and dynamic balances of patients with acromegaly and impact of exercise on balance. Pituitary 2019;22:497-506.

Han YG, Lee SW, Yun CK. The immediate influence of various wholebody vibration frequency on balance and walking ability in children with cerebral palsy: a pilot study. J Exerc Rehabil 2019;15:597-602.

Himmelmann K, Uvebrant P. The panorama of cerebral palsy in Sweden part XII shows that patterns changed in the birth years 2007-2010. Acta Paediatr 2018;107:462-468.

Inamdar K, Molinini RM, Panibatla ST, Chow JC, Dusing SC. Physical therapy interventions to improve sitting ability in children with or atrisk for cerebral palsy: a systematic review and meta-analysis. Dev Med Child Neurol 2021;63:396-406.

Jung KM, Choi JD. The effects of active shoulder exercise with a sling suspension system on shoulder subluxation, proprioception, and upper extremity function in patients with acute stroke. Med Sci Monit 2019; 25:4849-4855.

Ko SE, Kim YH, Lee SW. The Effects of trunk stabilization exercises using a sling on motor development and balance in infant with development disability. Adv Sci Technol Lett 2016;132:161-166.

Krigger KW. Cerebral Palsy: an overview. Am Fam Physician 2006;73: 91-100.

Kim DH, An DH, Yoo WG. The relationship between trunk control and upper limb function in children with cerebral palsy. Technol Health Care 2018a;26:421-427.

Kim YW, Kim NY, Chang WH, Lee SC. Comparison of the therapeutic effects of a sling exercise and a traditional stabilizing exercise for clinical lumbar spinal instability. J Sport Rehabil 2018b;27:47-54.
Lee JS, Lee HG. Effects of sling exercise therapy on trunk muscle activation and balance in chronic hemiplegic patients. J Phys Ther Sci 2014;26: 655-659.

Lee NY, Lee EJ, Kwon HY. The effects of dual-task training on balance and gross motor function in children with spastic diplegia. J Exerc Rehabil 2021;23:21-27.

Lee PY, Huang JC, Tseng HY, Yang YC, Lin SI. Effects of trunk exercise on unstable surfaces in persons with stroke: a randomized controlled trial. Int J Environ Res Public Health 2020;17:9135.

Lehman GJ, Hoda W, Oliver S. Trunk muscle activity during bridging exercises on and off a Swiss ball. Chiropr Osteopat 2005;13:14.

Maeo S, Chou T, Yamamoto M, Kanehisa H. Muscular activities during sling- and ground-based push-up exercise. BMC Res Notes 2014;7:192.

Mau-Moeller A, Behrens M, Finze S, Bruhn S, Bader R, Mittelmeier W. The effect of continuous passive motion and sling exercise training on clinical and functional outcomes following total knee arthroplasty: a randomized active-controlled clinical study. Health Qual Life Outcomes 2014;12:68.

Moraes AG, Copetti F, Angelo VR, Chiavoloni LL, David AC. The effects of hippotherapy on postural balance and functional ability in children with cerebral palsy. J Phys Ther Sci 2016;28:2220-2226.

Msall ME, DiGaudio K, Rogers BT, LaForest S, Catanzaro NL, Campbell J, Wilczenski F, Duffy LC. The functional independence measure for children (WeeFIM). Conceptual basis and pilot use in children with developmental disabilities. Clin Pediatr (Phila) 1994;33:421-430.

Nepocatych S, Ketcham CJ, Vallabhajosula S, Balilionis G. The effects of unstable surface balance training on postural sway, stability, functional ability and flexibility in women. J Sports Med Phys Fitness 2018;58: 27-34.

O'Sullivan PB, Phyty GD, Twomey LT, Allison GT. Evaluation of specific stabilizing exercise in the treatment of chronic low back pain with radiologic diagnosis of spondylolysis or spondylolisthesis. Spine 1997; 22:2959-2967.

Ottenbacher KJ, Msall ME, Lyon N, Duffy LC, Ziviani J, Granger CV, Braun S, Feidler RC. The WeeFIM instrument: its utility in detecting change in children with developmental disabilities. Arch Phys Med Rehabil 2000;81:1317-1326.

Park EY, Kim WH, Choi YI. Factor analysis of the WeeFIM in children with spastic cerebral palsy. Disabil Rehabil 2013;35:1466-1471.

Park J, Lee S, Hwangbo G. The effects of a bridge exercise with vibration training and an unstable base of support on lumbar stabilization. J Phys Ther Sci 2015;27:63-65.

Park JH, Hwangbo G. The effect of trunk stabilization exercises using a sling on the balance of patients with hemiplegia. J Phys Ther Sci 2014; 26:219-221. 
Prodinger B, O'Connor RJ, Stucki G, Tennant A. Establishing score equivalence of the Functional Independence Measure motor scale and the Barthel Index, utilising the International Classification of Functioning, Disability and Health and Rasch measurement theory. J Rehabil Med 2017;49:416-422.

Rosenbaum P, Paneth N, Leviton A, Goldstein M, Bax M, Damiano D, Dan B, Jacobsson B. A report: the definition and classification of cerebral palsy April 2006. Dev Med Child Neurol Suppl 2007;109:8-14.

Rosenbaum PL, Walter SD, Hanna SE, Palisano RJ, Russell DJ, Raina P, Wood E, Bartlett DJ, Galuppi BE. Prognosis for gross motor function in cerebral palsy: creation of motor development curves. JAMA 2002; 288:1357-1363.

Santamaria V, Khan M, Luna T, Kang J, Dutkowsky J, Gordon AM, Agraw- al SK. Promoting functional and independent sitting in children with cerebral palsy using the robotic trunk support trainer. IEEE Trans Neural Syst Rehabil Eng 2020;28:2995-3004.

Schubert M, Beck S, Taube W, Amtage F, Faist M, Gruber M. Balance training and ballistic strength training are associated with task-specific corticospinal adaptations. Eur J Neurosci 2008;27:2007-2018.

Vikne J, Oedegaard A, Laerum E, Ihlebaek C, Kirkesola G. A randomized study of new sling exercise treatment vs traditional physiotherapy for patients with chronic whiplash-associated disorders with unsettled compensation claims. J Rehabil Med 2007;39:252-259.

Yavuzer G, Eser F, Karakus D, Karaoglan B, Stam HJ. The effects of balance training on gait late after stroke: a randomized controlled trial. Clin Rehabil 2006;20:960-969. 